\title{
LICITAÇÕES NO MERCOSUL: UMA ANÁLISE COMPARATIVA ENTRE BRASIL E URUGUAI
}

\author{
Maria Dolores Pohlmann Velasquez ${ }^{1}$
}

\begin{abstract}
RESUMO
Presente a relevância e o montante das compras governamentais de profundo impacto na economia de qualquer país, aguçada a curiosidade acerca do trato governamental à questão no âmbito do Mercosul, inicialmente pretendeu-se um estudo, não exaustivo entre as legislações do Brasil e da República Oriental do Uruguai. A partir de uma análise comparativa sobre as legislações vigentes no Brasil e Uruguai a pesquisa verificou os caminhos percorridos num procedimento licitatório com vistas a detectar os possíveis pontos de convergência entre as tramitações. De forma geral o estudo comprovou num primeiro momento que as previsões legais de ambos os países são bastante coincidentes. De igual sorte, em análise comparativa verificou-se que a República Oriental do Uruguai possui legislação mais genérica com relação ao Brasil. Em resumo, o Uruguai ao prever as normas gerais, os princípios de licitações e contratos o faz sem aprofundar-se nas tramitações processuais e normas de fornecimento e/ou execução, o que já foi objeto de regulamentação no Brasil. E assim, por não serem legislações excludentes, revelamse excelentes corpos legais para base de legislação comum na hipótese de o Mercosul vir a decidir por compras conjuntas no âmbito governamental.
\end{abstract}

Palavras chave: Mercosul - Legislação - Licitações

\section{ABSTRACT}

Considering the importance and amount of governmental purchases of weighty impact on the economy of any country, sharpened the curiosity towards the

\footnotetext{
${ }^{1}$ Contadora e Professora da Universidade Federal de Santa Maria. Especialista em Métodos Quantitativos. Email-mdolores@smail.ufsm.br
} 
governmental treaty in the Mercosul realm, initially a non-exhaustive study between the Brazilian and the Uruguayan legislation was intended. Beginning with a comparative analysis over the current legislations in Brazil and Uruguay the research verified how the bidding procedures were performed expecting to detect possible converging points among the procedures. In a general way the study proved at a first moment that the legal specifications of both countries are very coincident. In the same way, in a comparative analysis it was found that The Oriental Republic of Uruguay possesses a more generic legislation in relation to Brazil. In short, Uruguay specifies general norms, bidding principles and contracts, without going into the process' procedures and rules of supply and/or execution, Brazil, differently, has already legally recognized them. In this way, because they are not excluding legislations, they are excellent legal structures to orient and base the common legislation in the hypothesis of the Mercosul deciding to unify purchases at governmental level.

Key-words: Mercosul, legislation, bidding.

\section{INTRODUÇÃO}

O Mercado Comum do Sul - Mercosul, criado seguindo uma tendência mundial de formação de blocos econômicos regionais, foi efetivado em 26 de março de 1991 através do Tratado de Assunção, tendo o Brasil, Argentina, Uruguai e Paraguai como países integrantes do bloco.

Durante a evolução do Mercosul pôde-se considerar primeiramente duas etapas: a primeira, referente à criação da Zona de Livre Comércio iniciada em 1994, que pudesse eliminar todas as barreiras comerciais entre os integrantes do grupo. A segunda, implantada em 1995 trata-se da etapa de integração definida como União Aduaneira, onde além do livre comércio entre os países parceiros existe a aplicação de uma Tarifa Externa Comum (TEC) ao comércio com terceiros países.

Passados treze anos desde a sua criação, o Mercosul encontra-se hoje entre as maiores economias mundiais, ao lado do NAFTA (Acordo de Livre Comércio da 
América do Norte), União Européia e Japão, razão pela qual, representa um dos principais alvos de investimentos do mundo.

Entretanto, a consolidação do bloco vem ocorrendo de forma gradual indicando que há muito ainda a fazer, inclusive na atual fase de integração. Nesse sentido, com o objetivo de finalizar as divergências, vem sendo desenvolvido pelos países membros a criação de mecanismos para solução das controvérsias. Dentre eles, como meta até o final de 2006, encontram-se os serviços, investimentos e as compras governamentais, onde, de forma mais específica, insere-se o presente estudo.

Salienta-se ainda que até o momento inexiste um acordo específico a respeito das licitações públicas no âmbito do Mercosul, aplicando-se assim, no que couber, as regras gerais do tratado firmado.

\section{DESENVOLVIMENTO}

Todos os setores da sociedade são de certa forma atingidos pela globalização, na medida que tal fenômeno acarreta conseqüências nos aspectos sociais, culturais e econômicos das nações. Para acompanhar essa evolução e em busca de novos caminhos e oportunidades as empresas vem inserindo-se no mercado internacional de forma cada vez mais rápida, sob pena de serem alijadas do mundo dos negócios.

Nesse processo globalizado, as compras governamentais passam a ter papel relevante na medida que contribuem sobremaneira para o desenvolvimento sócioeconômico das nações.

No caso do Mercosul, o assunto passou a ter atenção especial por parte dos governantes integrantes do bloco no sentido de dirimir as barreiras existentes, uma vez que os abalos econômicos sofridos pelos países interferem direta ou diretamente em qualquer modelo de integração.

$O$ alto benefício que o movimento das compras públicas traz para o processo de integração, bem como para as empresas fornecedoras de bens e/ou serviços, faz com que os países integrantes do bloco comecem a pensar em novas sistemáticas e 
modelos com vistas a agilizar esse campo da integração até o momento pouco explorado.

Nesse sentido, o presente estudo, ao efetuar uma análise comparativa entre aos procedimentos adotados pelos países Brasil e Uruguai com referência as licitações públicas, indubitavelmente será um facilitador que muito poderá contribuir para o desenvolvimento do tema em questão.

\section{REVISÃO BIBLIOGRÁFICA}

A formação de blocos econômicos regionais vem evoluindo há décadas no sentido de acompanhar o cenário atual de uma economia globalizada. Os países integrantes de um bloco econômico ficam mais potentes em suas negociações, uma vez que passam a enfrentar, não de forma isolada, mas como bloco frente a outros blocos econômicos.

Conforme Rosa (1999:19):

"O atual cenário mundial aponta para uma crescente internacionalização da economia, que se manifesta pelo surgimento de blocos econômicos continentais e/ou regionais, exigindo uma economia aberta e a prática de livre comércio entre os países que formam esses blocos. Somam-se esforços para ampliação das relações socioculturais entre esses países, demonstrando que nos dias atuais se procura por meio da integração o desenvolvimento sócioeconômico, com o intuito de se proteger e/ou fortalecer, para enfrentar a competitividade em nível global."

Entretanto, a viabilidade do processo de integração decorre de mudanças em vários aspectos como: educativo, cultural, administrativo, tecnológico e econômico a serem promovidas pelos países no sentido de atender às necessidades estabelecidas pelo novo modelo de desenvolvimento.

A economia globalizada permite o ingresso de novos competidores num mercado até então explorado pelas empresas locais, as quais, em troca terão acesso a outros mercados, pela via da reciprocidade (Bittencourt, 2002).

A tendência mundial de formação de blocos econômicos regionais iniciou com a criação da Comunidade Econômica Européia através do Tratado de Roma, de 25 
de março de 1957. Na América Latina, tal integração vem sendo conquistada a partir da consolidação do Mercado Comum do Sul-Mercosul, formado pelo Brasil, Argentina, Paraguai e Uruguai, em 26 de março de 1991, através da assinatura do Tratado de Assunção.

Nesse contexto, os países envolvidos procuram inserir-se de forma mais competitiva na economia internacional estimulados pela abertura de mercados com prováveis benefícios nos campos social, político, cultural e econômico.

Nas palavras de Santos (1993:98):

Dentro dessa perspectiva mais ampla (econômica, sociológica, política e cultural), a integração latino-americana ocupará um papel fundamental para o avanço de cada país e região, assim como o avanço de cada localidade, região e país deverá ser a précondição de uma verdadeira integração continental.

Nessa dinâmica, as compras governamentais causam grande impacto, responsáveis que são por grande parte do produto interno dos países. Com o objetivo de reduzir as barreiras que limitam o intercâmbio, promovendo a união das economias entre os países, os mercados governamentais, até aqui de certa forma fechados, tendem a ampliar-se no sentido de não impor restrições à participação de estrangeiros nas licitações públicas ocorridas entre os países-membros do Mercosul. Reforça essa tendência o interesse do atual governo em estabelecer para os próximos quatro anos mecanismos de solução de controvérsias, sendo um dos alvos diretos as compras governamentais.

No Brasil, o tema licitações teve início ainda em 1922 através do Código de Contabilidade Pública. Atualmente é regido pela Lei № 8.666/93 e posteriores alterações. A referida lei que regulamenta o artigo 37, caput, inciso XXI da Constituição Federal/88, institui normas para licitações e contratos da Administração Pública. A licitação é considerada um procedimento administrativo onde, a partir do princípio da isonomia entre os participantes, busca a proposta mais vantajosa de contrato. Mas então, como tal assunto é tratado no âmbito internacional, de forma mais específica, na esfera do Mercosul? Seguramente, um dos fatores que dificultam a integração daquele bloco é a existência de diferenças nas legislações de seus países-membros, dificuldade encontrada inclusive por nações mais avançadas. 
A respeito da harmonização para o caso das compras governamentais assim manifestou-se Dromi (1997:584): "visto que a adaptação das regras aplicadas a licitações e contratos denotam também a transparência pública. Não podemos, em âmbito de Mercosul, ter um ordenamento no qual um país siga certos requisitos, e outro, requisitos diversos."

Para Borges Barbosa (1997:27):

Não se tem até o momento, um acordo específico sobre licitações públicas no âmbito do Mercosul; aplicam-se, porém, a todos os procedimentos administrativos, dentre eles seguramente as licitações, as regras genéricas do Tratado, no que tiverem pertinência, assim como as do tratado específico entre Brasil e Argentina que instituiu as empresas binacionais.

A expressão licitação internacional tem gerado interpretações diversas, levando a uma conclusão incorreta sobre o que realmente tal expressão representa. $\mathrm{Na}$ realidade, é um procedimento licitatório ocorrido em solo brasileiro que proporciona, a participação de empresas brasileiras, bem como de empresas estrangeiras com domicílio em outro país, desde que atendam a algumas exigências, conforme $\circ \S 4^{\circ}$, artigo 32 da Lei ํo 8.666/93. Tais exigências (apresentação tanto quanto possível de documentos equivalentes), dispostas nos $\S$ $1^{\circ}, 2^{\circ}$ e $3^{\circ}$ do artigo 32 da mesma lei, referem-se a documentos que deverão ser apresentados pelos licitantes como condição de habilitação, a qual representa a primeira fase do processo.

O inciso II, $\S 1^{\circ}$ do artigo $3^{\circ}$ daquele dispositivo veda aos agentes públicos tratamento diferenciado de natureza comercial, legal, trabalhista, previdenciária ou qualquer outra, entre empresas brasileiras e estrangeiras. Entretanto, apesar da intenção isonômica da lei entre licitantes brasileiros e estrangeiros, o alcance da regra torna-se incalculável e temeroso diante da diversidade de regras jurídicas de outros países envolvidos que poderão interessar-se pelo certame (Bittencourt, 2002).

Então, como trabalhar com essas diferenças? A resposta a esse questionamento faz parte do presente estudo.

As modalidades de licitações previstas pela legislação brasileira são Convite, Tomada de Preços, Concorrência, Concurso, Leilão e o Pregão (criada mais recentemente, através de lei específica). Utiliza-se a Concorrência sempre que se 
desejar ampliar o universo do competitório, geralmente para obtenção de tecnologias mais avançadas ou até para buscar redução de preços de monopólios nacionais, estendendo-se a intenção às empresas internacionais com domicílios fora do Brasil. Admite-se a Tomada de Preços quando o órgão ou entidade dispuser de cadastro internacional de fornecedores e ainda o Convite sempre que não houver fornecedor do bem ou serviço no país.

Ao propor a análise comparativa entre Brasil e Uruguai, analisou-se a documentação prevista nas legislações específicas daqueles paises, procurando identificar os pontos assimétricos entre tais dispositivos.

Na opinião de Laso (1991:553):

As vantagens da licitação são indubitáveis, pois assegura geralmente os preços mais vantajosos, elimina os favoritos e os conluios dolosos na contratação administrativa, e permite um controle eficaz. Apesar disso, ela tem seus inconvenientes, pois o procedimento resulta às vezes lento e nem sempre impede a aceitação de ofertas contrárias ao interesse público. Porém, o saldo é tão favorável que não dúvidas sobre sua conveniência.

A lei de licitações vigente, considerada demasiadamente burocrática em alguns de seus dispositivos, para alguns empresários brasileiros, deveria ser alterada em algumas práticas e procedimentos para os países do bloco de forma a garantir nos certames internacionais a maior participação de empresas integrantes daqueles países, garantindo, inclusive, a plena transparência do processo como um todo.

\section{RESULTADOS E DISCUSSÕES}

A partir de uma análise comparativa sobre as legislações referentes as compras governamentais - Brasil e Uruguai, o presente trabalho buscou através de um estudo avaliativo um perfeito entendimento sobre a legislação e procedimentos adotados por tais países com relação às licitações públicas.

Partindo de uma visão geral, pontos considerados cruciais num processo licitatório foram estabelecidos e considerados portanto, objetos da pesquisa. 
No Brasil, o dispositivo legal vigente é a Lei no 8.666 de 21 de junho de 1993 com posteriores alterações. No Uruguai, as licitações públicas inserem-se na Seção 2 de um Texto Ordenado de Contabilidade e Administração Financeira do Poder Legislativo, datado de outubro de 1988.

De início verificou-se que os princípios licitatórios são considerados em ambas as legislações. No Brasil o artigo $3^{\circ}$ da lei de regência cita como básicos os princípios da legalidade, da impessoalidade, da moralidade, da igualdade, da publicidade, da probidade administrativa, da vinculação ao instrumento convocatório, do julgamento objetivo e dos que Ihes são correlatos. Nenhum artigo do dispositivo uruguaio faz referência de forma específica ao assunto, à excessão dos princípios da igualdade e da publicidade que estão contemplados, de forma indireta nos artigos 34, 42, 47, 48 e 49 do texto citado.

Em ambas as legislações constam a existência de Comissões Licitatórias. O Uruguai prevê no artigo 57 uma ou várias Comissões Assessoras de Adjudicação, designadas pela autoridade superior com o encargo de julgar e informar a proposta mais vantajosa aos interesses do Estado. Entretanto, as comissões atuam nas contratações cujo montante supere \$471.000,- (quatrocentos e setenta e um mil pesos) $)^{2}$. As demais poderão ser processadas por funcionários designados para tais atos. No Brasil, esse procedimento de substituir o papel da comissão por servidor específico é admitido em situações especiais como na dispensa e inexigibilidade de licitação, e ainda, de forma excepcional nas pequenas unidades administrativas para as licitações de menor porte (Convite) quando ocorrer escassez de pessoal para comporem a dita comissão. A comissão será considerada permanente quando instituída para processar e julgar de forma geral todas as licitações da entidade. Será tratada como especial quando for instaurada para determinadas licitações, ou seja, com atuação definida nos casos para os quais foi designada. $O \S 2^{\circ}$ do artigo 51 da lei respectiva prevê ainda uma comissão de recebimento de material para o recebimento de bens. $O \S 5^{\circ}$ do mesmo artigo cita a comissão de concurso para os casos de seleção de um projeto intelectual.

\footnotetext{
${ }^{2}$ ROU-Instituo Nacional de Estadística, set/dez-2004
} 
As modalidades de licitação, consideradas relevantes pela lei brasileira, são determinadas a partir do valor estimado para a contratação. A concorrência, a tomada de preços, o convite, o concurso e o leilão foram estabelecidos pelo artigo 22 da lei de regência. A Lei oㅜ 10.520 de 17 de julho de 2002 instituiu o pregão como a mais recente modalidade licitatória, aplicável qualquer que seja o valor estimado. Sendo assim, tendo em vista o valor estimado, o artigo 23 da Lei 8.666/93 fixou:

Para obras e serviços de engenharia:

- Convite: até $\mathrm{R} \$ 150.000,00$

- Tomada de Preços: até $\mathrm{R} \$ 1.500 .000,00$

- Concorrência: acima de $\mathrm{R} \$ 1.500 .000,00$

Para compras e serviços comuns:

- Convite: até $\mathrm{R} \$ 80.000,00$

- Tomada de Preços: até $\mathrm{R} \$ 650.000,00$

- Concorrência: acima de $\mathrm{R} \$ 650.000,00$

$\mathrm{O}$ artigo 33 da lei uruguaia estabelece:

- Licitação pública:

- Quando o contrato derivar de gastos de funcionamento (saídas para o Estado)

- Remate ou licitação pública:

- Quando o contrato derivar de entrada de recurso

- Licitação abreviada:

- Quando o montante da operação não exceder a \$1.570.000,- (um milhão quinhentos e setenta mil pesos) ${ }^{3}$.

Afora as modalidades licitatórias previstas, a lei de licitações brasileira prevê duas situações consideradas como excessões à regra de licitar: dispensa e inexigibilidade de licitação. Considera-se dispensa os casos em que embora sendo possível a licitação a mesma pode ser dispensada pela autoridade administrativa baseada nos casos previstos no artigo 24. De outra parte a inexigibilidade deve ser

\footnotetext{
${ }^{3}$ Instituto Nacional de Estadistica-ROU-set/dez 2004
} 
aplicável sempre que for impossível licitar por absoluta falta de competição, conforme consta do "caput" do artigo 25 da Lei o 8.666/93.

De modo semelhante o Uruguai admite aquisições/contratações sem licitação quando prevê no item 2 do artigo 33 a compra direta comum, por baixo valor. Relacionados no item 3 do mesmo artigo encontram-se os casos especiais para aquisições/contrações diretas, os quais deverão ser em razão de interesse público e determinados pelo ordenador de despesa.

Os registros cadastrais constam da legislação uruguaia através do artigo 66. Tal dispositivo indica que em toda licitação pública ou abreviada e para as contratações diretas de obras públicas cujo montante exceda a $\$ 1.570 .000$,- (um milhão quinhentos e setenta mil pesos) ${ }^{4}$ será exigido o Certificado de Inscrição (aptidão econômico-financeira) demonstrando capacitação técnica para a eventual contratação. $O$ documento deve ser expedido pelo Registro Nacional de Empresas de Obras Públicas do Ministério de Transporte e Obras Públicas. O artigo 34 da Lei no 8.666/93 dedica em sua Seção III especial atenção ao assunto. Ao facultar aos órgãos públicos a emissão de registro cadastral o legislador brasileiro procurou simplificar a agilizar o procedimento licitatório na medida que sua apresentação por ocasião da abertura do certame, dispensa o exame do rol de documentos exigidos para a habilitação dos licitantes constantes dos artigos 28 a 31 da lei de licitações. Salienta-se que a exigência de tais documentos poderá ser dispensada, no todo ou em parte, nos casos de Convite, Concurso e Leilão, sempre para fornecimento de bens para pronta entrega.

Outro ponto abordado no estudo refere-se ao edital, também conhecido como ato convocatório. Instrumento utilizado com a intenção inclusive de noticiar a licitação, tem por finalidade primeira nortear o processo como um todo. Ambos os dispositivos (brasileiro e uruguaio) estabelecem algumas regras e condições comuns que devem conter o edital: a descrição do objeto, o lugar, o dia e a hora para apresentação das propostas. Todavia, o artigo 45 do texto uruguaio prevê a possibilidade de preços diferentes ofertados pelo mesmo licitante, variáveis de

\footnotetext{
${ }^{4}$ Instituto Nacional de Estadistica-ROU-set/dez 2004
} 
acordo com a quantidade a ser fornecida quando o edital não prever quantidades. Situação não prevista pela legislação brasileira, que fixa objeto claro e quantitativos precisos.

A fase externa do processo licitatório inicia quando a Administração torna público o interesse em licitar. Para tanto, a legislação brasileira através do artigo 21 e seus incisos prevê que os avisos contendo os resumos dos editais deverão ser publicados no Diário Oficial da União e/ou Estado e/ou Distrito Federal, e também em jornal de grande circulação. O mesmo artigo estabelece ainda os prazos mínimos entre a publicação e o dia da abertura dos envelopes, os quais variam de acordo com a modalidade e tipos de licitação adotados. Assim, tal prazo será de 45 (quarenta e cinco) dias para as modalidades concurso e concorrência (tipo melhor técnica ou técnica e preço); 30 (trinta) dias para as modalidades de concorrência (tipo menor preço) e tomada de preço (tipo melhor técnica ou técnica e preço); 15 (quinze) dias para a modalidade tomada de preços (tipo menor preço) e 5 (cinco) dias úteis para a modalidade convite. $\mathrm{Na}$ modalidade pregão conforme a lei respectiva o dito prazo é de 8 (oito) dias úteis.

A legislação uruguaia por meio do artigo 47 estabelece que a publicação em Diário Oficial e outro jornal de circulação nacional para as licitações públicas e remates deverá acontecer no prazo mínimo de 15 (quinze) dias. Quando ocorrer a possibilidade de participação de licitantes radicados no exterior tal prazo será de 30 (trinta) dias. Conforme o interesse público e a urgência, o ordenador de despesa poderá reduzir o prazo de publicação, desde que não seja inferior a 5 (cinco) e 10 (dez) dias, respectivamente. No caso de licitação abreviada o prazo estabelecido é de no mínimo 3 (três) dias, podendo ser reduzido para 2 (dois) dias pelos mesmos motivos acima citados. Quando o valor a ser contratado for superior a $\$ 235.500$,(duzentos e trinta e cinco mil e quinhentos pesos) ${ }^{5}$ os avisos de edital deverão ser noticiados em publicações especializadas em compras e sem custo para o Estado.

A partir da publicação segue-se a abertura dos envelopes. $O$ artigo 56 do texto uruguaio e 0 $\S 1^{\circ}$ do artigo 43 da lei brasileira convergem quanto ao procedimento adotado o qual será realizado em ato público na presença dos

\footnotetext{
${ }^{5}$ ROU-Instituto Nacional de Estadística, set/dez-2004
} 
funcionários designados e/ou da Comissão, assim como, dos licitantes presentes. Finalizado 0 ato será lavrada ata circunstanciada que será assinada pelos presentes à sessão.

Outro aspecto que merece comparação refere-se ao artigo 56 acima citado e ao $\S 3^{\circ}$ do artigo 48 da Lei 8.666/93. Esse diz que quando todos os licitantes forem inabilitados ou todas as propostas forem desclassificadas a administração poderá fixar o prazo de oito dias úteis para apresentação de nova documentação ou de outras propostas. No caso de licitação na modalidade convite o prazo poderá ser reduzido para três dias úteis. Semelhante possibilidade aventa a lei uruguaia quando dispôe no aludido artigo o prazo de dois dias, para todos os licitantes, independentes de inabilitação e/ou desclassificação.

De outro lado, as formas de apresentação das propostas diferem quando analisa-se o artigo 32 combinado com o inciso IV do artigo 38 da lei ํㅜ 8.666/93 e o artigo 54 do texto ordenado. A legislação brasileira determina que todos os documentos anexos ao processo licitatório sejam em original ou por qualquer processo de cópia autenticada por cartório competente ou por servidor da administração. As publicações em órgão da imprensa oficial também serão aceitos. O Uruguai admite propostas via fax, teléx e outros meios similares, desde que sejam recebidas em tempo hábil à abertura do ato.

Os tipos de licitação claramente previstos na legislação brasileira pelo artigo 45 , $\S 1^{0}$ como: menor preço, melhor técnica, técnica e preço e maior oferta encontram-se diretamente ligados ao critério de julgamento. O mesmo destaque não dispôs a legislação uruguaia quando no art. 59 do texto analisado dispõe que a adjudicação se fará a partir da proposta mais conveniente.

A adjudicação do objeto licitado ocorre quando decide-se pela primeira colocada na condição de vencedora. Tal atribuição cabe à autoridade superior para ambas as legislações estudadas, a partir do julgamento e classificação das propostas efetuadas pela Comissão de Licitação e/ou Comissão Assessora.

De todos os atos praticados no procedimento cabe recurso administrativo no sentido de proteger e defender os direitos dos licitantes. A respeito divergem as legislações estudadas. $O$ inciso I do artigo 109 da lei brasileira estabelece 0 
cabimento de recurso no prazo de dois dias úteis (convite) e cinco dias úteis (demais modalidades) a contar da intimação do ato ou da lavratura da ata, nos casos de: habilitação ou inabilitação de licitantes, julgamento das propostas, anulação ou revogação da licitação, indeferimento do pedido, alteração ou cancelamento de registros cadastrais e rescisão de contrato determinada por ato unilateral. Quando os questionamentos referirem-se ao ato convocatório, a lei respectiva trata como "impugnação ao edital". O $\S 1^{\circ}$ do artigo 41 estabelece o prazo de até cinco dias úteis antes da abertura dos envelopes quando o pedido partir de qualquer cidadão (não necessáriamente licitante). No caso de licitante o prazo deve ser reduzido para dois dias úteis, em atendimento ao $\S 2^{\circ}$ do mesmo artigo.

A lei uruguaia não faz previsão específica quanto a impugnação do edital. $O$ artigo 62 diz que os procedimentos poderão ser impugnados mediante a interposição de recursos a partir do dia seguinte a notificação ou publicação, os quais deverão ser encaminhados no prazo de quarenta e oito horas.

Nesse aspecto, percebe-se a possibilidade de desistência de apresentação de recurso em ambos os dispositivos analisados.

Quando o procedimento competitivo envolver valor $\$ 6.280 .000,00$ (seis milhões duzentos e oitenta mil pesos) ${ }^{6}$ o artigo 58 do texto vigente estabelece que após julgado mas antes da adjudicação a comissão assessora deverá, no prazo de vinte e quatro horas proporcionar vistas a todos os ofertantes do decidido, que terão cinco dias para apresentar suas considerações. Os recorrentes deverão encaminhar cópia dos questionamentos ao Tribunal de Contas que terá vinte e quatro horas para manifestação.

Observa-se que os recursos em ambos os países não são endereçados às comissões e sim à autoridade superior e/ou ao Tribunal de Contas.

Os quantitativos decorrentes de contrato estão sujeitos a alterações que poderão ocorrer desde que de acordo com lei. A respeito, destaca-se 0 § $1^{\circ}$ do artigo 65 do dispositivo brasileiro em que o contratado fica obrigado a aceitar os acréscimos ou supressões até $25 \%$ (vinte e cinco por cento) nas obras, serviços ou

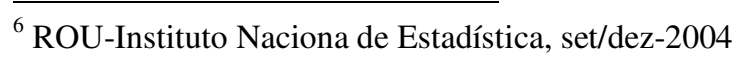


compras. No caso de reforma de edifícios ou de equipamentos o limite estabelecido é de $50 \%$ (cinquenta por cento) para os seus acréscimos.

Entretanto, nas supressões e por acordo das partes esses limites poderão ser excedidos.

No Uruguai, tais limites encontram-se no artigo 63. Os aumentos ou diminuições variam entre 10\% (dez por cento) e 20\% (vinte por cento) a partir do valor original. Não obstante, quando houver acordo do adjudicatário tanto os acréscimos como as supressões poderão exceder esses limites. Porém, em nenhum caso os aumentos poderão superar 100\% (cem por cento) do total contratado.

Ainda sobre contratos, outro ponto a destacar relaciona-se com as garantias contratuais prevista na lei brasileira através do artigo 56. O $\S 1^{\circ}$ do citado artigo destaca três modalidades de garantia: caução em dinheiro ou títulos da dívida pública, seguro-garantia ou fiança bancária, cabendo ao contratado a opção. O valor caucionado não excederá a 5\% (cinco por cento) do valor do contratado. Para obras, serviços e fornecimento de grande vulto esse limite poderá ser ampliado para $10 \%$ (dez por cento). De outro modo, a lei uruguaia conforme o artigo 55 considera as seguintes modalidades: depósito em dinheiro ou em valores públicos, fiança ou aval bancário e apólice de seguro e estabelece entre 1\% (um por cento) e 5\% (cinco por cento) os valores a serem considerados, no caso de manutenção de oferta e cumprimento de contrato, respectivamente. Ademais, o organismo licitante poderá desde que por razões fundadas aumentar tais percentuais ou estabelecer outras modalidades de garantia desde que previstas no edital respectivo.

Entretanto, quando o valor da licitação for inferior ao limite da licitação abreviada, ou seja, $\$ 1.570 .000$,- (um milhão quinhentos e setenta mil pesos) ${ }^{7}$ não será exigida garantia de manutenção de oferta. De igual modo quando o valor licitado for o equivalente a $40 \%$ do valor anterior, isto é, $\$ 628.000,00$ ( seiscentos e vinte e oito mil pesos) ${ }^{8}$ a garantia do fiel cumprimento de contrato também deverá ser dispensada.

\footnotetext{
${ }^{7}$ ROU-Instituo Nacional de Estadística, set/dez-2004

${ }^{8}$ ROU-Instituto Nacional de Estadística, set/dez-2004
} 


\section{3. CONSIDERAÇÕES FINAIS}

O presente estudo baseado nas legislações adotadas nos procedimentos licitatórios no Brasil e Uruguai, demonstrou através de uma análise comparativa as práticas adotadas por tais países com relação às compras governamentais. Para tanto, e sem a pretensão de exaurir o assunto, foram adotados como parâmetros alguns pontos considerados relevantes num processo licitatório.

Inicialmente pode-se observar com relação aos dispositivos analisados que o Uruguai em termos de licitações públicas ainda não possui legislação específica, uma vez que tal assunto encontra-se inserido num texto ordenado de contabilidade e administração financeira do Poder Legislativo, de outubro de 1988. Em semelhante situação encontrava-se o Brasil quando o Decreto-Lei no 200/67 que dispõe sobre a organização da administração federal e estabelece diretrizes para a reforma administrativa norteava as compras públicas. A partir de 1986 as compras governamentais do Brasil passam a receber tratamento exclusivo através do Decreto-Lei $n^{\circ} 2300$ revogado pela Lei ํํ 8.666/93 que institui normas para licitações e contratos da administração pública, seguida de alterações posteriores e com vigência atual.

Com referência aos princípios licitatórios verificou-se que os da igualdade e da publicidade constam de forma expressa nas duas legislações.

No Brasil as Comissões de Licitações são mais atuantes. Enquanto que no Brasil sua dispensa é admitida em casos especiais, no Uruguai sua atuação está prevista somente nas contratações superiores a $\$ 471.000$,- (quatrocentos e setenta e um mil pesos) $)^{9}$.

Em ambos os países analisados o que define num primeiro momento as modalidades de licitação a serem aplicadas é o valor estimado para aquisição/contratação. Entretanto, neste aspecto as legislações tornam-se mais divergentes. A legislação brasileira prevê a concorrência, a tomada de preços, o convite, o concurso, o leilão e o pregão como formas de licitar. Como formas direta de contratação, portanto sem licitação, encontram-se a dispensa e a inexigibilidade.

${ }^{9}$ ROU-Instituo Nacional de Estadística, set/dez-2004 
A licitação pública, o remate e a licitação abreviada são as modalidades praticadas no Uruguai. Para aquisições e/ou contratações sem licitação reconhece-se a compra direta para as aquisições de baixo valor e para os casos identificados como de interesse público.

Convém salientar que ambas as legislações previram aquisições/contratações diretas baseadas no valor a ser dispendido. No Brasil atualmente esse valor corresponde a $\mathrm{R} \$ \mathbf{8 . 0 0 0 , 0 0}$ (oito mil reais) equivalente a 10\% (dez por cento) da modalidade convite. No Uruguai o valor é de $\$ 78.500$,- (setenta e oito mil e quinhentos pesos) $)^{10}$ equivalente a $5 \%$ (cinco por cento) da licitação abreviada.

Ainda sobre as modalidades de licitação pode-se concluir que o convite (no Brasil), enviados no mínimo a três empresas do ramo equivale a licitação abreviada (no Uruguai), no qual são convidados no mínimo seis firmas do ramo.

Em específico, ambas as legislações admitem a possibilidade de que o número mínimo de licitantes não seja atingido, situação que deverá ser plenamente justificada, indicando inclusive as causas que impediram o cumprimento das normas estabelecidas.

Os registros cadastrais usados de forma sistemática nas licitações brasileiras é utilizado nas licitações uruguaias e contratações diretas para obras e, quando o montante a ser contratado for superior a $\$ 1.570 .000$.00 (um milhão quinhentos e setenta mil pesos) $)^{11}$.

Os editais, considerados como a lei interna da licitação, assemelham-se em sua forma geral. No entanto quanto as quantidades licitadas percebe-se uma enorme flexibilidade da lei uruguaia com relação à lei brasileira.

Com relação a publicação detectou-se que para os casos de interesse público ou urgência a lei uruguaia prevê redução de prazo de publicação. Essas situações são tratadas pela lei brasileira como dispensa de licitação e, de modo semelhante também prevê prazo diferenciado de publicação com relação a outras formas de contratar.

\footnotetext{
${ }^{10}$ ROU-Instituto Nacional de Estadística, set/dez-2004

${ }^{11}$ ROU-Instituto Nacional de Estadística, set/dez-2004
} 
Questões como a abertura dos envelopes, lavratura de ata circunstanciada e adjudicação foram considerados unânimes em ambas as legislações. Todavia,

a legislação brasileira estabelece como fases da licitação e, nessa ordem, a abertura dos envelopes, habilitação dos licitantes, classificação/julgamento das propostas, homologação e adjudicação. Essas etapas também foram verificadas na legislação uruguaia, embora de forma menos rigorosa quando permite a abertura das propostas de todos os licitantes, independentes de habilitados ou não. Sendo assim, no Uruguai a verificação dos documentos (habilitação no Brasil) é posterior à abertura das propostas. O Brasil, embora mais recentemente, evoluiu nesse sentido através da já comentada modalidade Pregão, que permite a inversão de fases justamente com o objetivo de agilizar o processo licitatório.

Outro ponto a destacar refere-se ao recebimento das propostas, onde a lei brasileira resguarda sigilo absoluto sobre os preços propostos até a abertura dos envelopes. Essa questão não é, pelo menos na mesma proporção, objeto de cuidado da lei uruguaia na medida que aceita o recebimento de propostas via fax e outros meios similares.

Ainda com relação as fases licitatórias, mais especificamente quanto ao julgamento do processo verificou-se que em ambos os países a proposta mais vantajosa não significa necessariamente a de menor preço, ou seja, outros fatores constantes do edital, como por exemplo, o atendimento às especificações do objeto licitado devem ser considerados.

Com relação aos recursos administrativos a lei brasileira estabelece prazos diversos conforme a modalidade licitatória, assim como para os casos de impugnação ao edital. O tratamento uruguaio, independente da modalidade adotada prevê o prazo diferenciado somente para os procedimentos a partir de $\$$ $6.280 .000,00$ (seis milhões duzentos e oitenta mil pesos) ${ }^{12}$.

Outro ponto divergente diz respeito as alterações de quantitativo nas aquisições e/ou contratações. No Brasil a administração está condicionada a aquisição de $75 \%$ (setenta e cinco por cento), em consequência, o contratado obriga-se a aceitar os aumentos e as supressões em até $25 \%$ (vinte e cinco por

\footnotetext{
${ }^{12}$ ROU-Instituo Nacional de Estadística, set/dez-2004
} 
cento) do total adquirido e/ou contratado. Por acordo das partes e nas supressões esses percentuais poderão ser ampliados. No Uruguai a situação oscila entre 10\% e $20 \%$ podendo exceder tais limites desde que por acordo entre as partes, não podendo ultrapassar 100\% (cem por cento) do total contratado.

Ao verificar as garantias contratuais percebe-se que afora as modalidades semelhantes entre os países estudados, a lei uruguaia prevê situações distintas para os casos de manutenção de oferta e cumprimento de contrato, situação não vislumbrada na legislação brasileira.

Diante do exposto, o estudo proporcionou uma visão detalhada, embora não exaustiva da legislação aplicada às licitações públicas - Brasil e Uruguai. Ao discorrer sobre pontos importantes num processo licitatório pode-se observar o grau de exigência das respectivas legislações, ou seja, no contexto legal foram identificadas as questões de maior ou menor relevância que cada país estudado considera no trato das compras governamentais.

\section{REFERÊNCIAS BIBLIOGRÁFICAS}

BITTENCOURT, Sidney. Estudos sobre Licitações Internacionais. Rio de Janeiro: Temas e Idéias, 2002.

BORGES, Denis B. Licitações, Subsídios e Patentes - Direito de Desenvolvimento Industrial. Rio de Janeiro: Lumen Juris, 1997.

BRASIL. Lei n. 8.666, de 21 de junho de 1993. Regulamenta o art. 37 da Constituição Federal, institui normas para licitações e contratos da Administração Pública e dá outras providências.

DROMI, Roberto. Informativo Licitações e Contratos. Paraná: Zênite, 1997.

ROSA, Paulo M. A Contabilidade no Mercosul. São Paulo: Atlas, 1999.

REPÚBLICA ORIENTAL DO URUGUAI. Texto ordenado de contabilidade e administração financeira. Outubro de 1998. Poder Legislativo. Instituto Nacional de Estadística. Montos limites de las adquisiciones estatales (TOCAF), setiembre-diciembre 2004.

SANTOS, Theotonio. Economia Mundial, Integração Regional e Desenvolvimento Sustentável. As novas tendências da economia mundial e a integração latino-americana. Petrópolis: Vozes, 1993. 